\title{
A HUMILDADE INTELECTUAL COMO OBJETIVO EMERGENTE NO ENSINO DE CIÊNCIAS: POSSIBILIDADES A PARTIR DE UMA ABORDAGEM INVESTIGATIVA NOS ANOS INICIAIS
}

\author{
INTELLECTUAL HUMILITY AS AN EMERGING OBJECTIVE IN SCIENCE TEACHING: \\ POSSIBILITIES FROM AN INVESTIGATIVE APPROACH IN THE EARLY YEARS
}

\author{
MATEUS LORENZON 1 \\ JACQUELINE SILVA DA SILVA²
}

\section{RESUMO}

Neste artigo discute-se as possibilidades de uma abordagem de ensino investigativa fomentar 0 desenvolvimento da virtude da humildade intelectual em crianças dos Anos Iniciais do Ensino Fundamental. 0 estudo decorre de uma pesquisa-ação realizada com crianças do $3^{\circ}$ Ano de uma escola pública localizada em Arroio do Meio/RS. 0 corpus da pesquisa foi produzido por meio de observações participantes, registros fotográficos, entrevistas e análise da documentação pedagógica, sendo interpretados por meio da Análise Textual Discursiva. Infere-se que o engajamento das crianças em propostas investigativas permite a constituição de uma imagem mais adequada da epistemologia do conhecimento, bem como perceberem a inexistência de uma hierarquia axiológica entre as diferentes formas de saber. Entende-se que o desenvolvimento destas habilidades é condição importante para a adoção de uma postura ética e dialógica em relação à sociedade, bem como o reconhecimento da incerteza e de sua própria incompletude.

Palavras-chave: Ensino por Investigação. Humildade Intelectual. Epistemologia. Ética. Ensino de Ciências.

\section{ABSTRACT}

This article discusses the possibilities of an investigative teaching approach to foster the development of intellectual humility in children in the Early Years of Elementary Education. The study stems from an action research carried out with children from the 3rd year of a school located in Arroio do Meio / RS. The research corpus was produced through participant observations, photographic records, interviews and analysis of the pedagogical documentation, being interpreted through the Discursive Textual Analysis. It is inferred that the engagement of children in investigative proposals allows the constitution of a more adequate image of the epistemology of knowledge, as well as realizing the inexistence of an axiological hierarchy between the different forms of knowledge. It is understood that the development of these skills is an important condition for the adoption of an ethical and dialogical posture in relation to society, as well as the recognition of uncertainty and its own incompleteness.

Keywords: Research Teaching. Intellectual Humility. Epistemology. Ethic. Science Teaching

\section{RESUMEN}

Este artículo analiza las posibilidades de un enfoque de enseñanza investigativa para fomentar el desarrollo de la humildad intelectual en los niños en los primeros años de la educación primaria. El estudio surge de una investigación-acción llevada a cabo con niños de $3^{\circ}$ año de una escuela ubicada en Arroio do Meio / RS. El corpus de investigación se produjo a través de observaciones de los participantes, registros fotográficos, entrevistas y análisis de la documentación pedagógica, siendo interpretado a través del Análisis Textual Discursivo. Se infiere que el

1 Graduado em Pedagogia - UNIVATES. Mestre em Ensino - UNIVATES. E-mail: mateusmlorenzon@gmail.com Orcid: https://orcid.org/0000$0001-9402-5820$

2 Doutora em Educação - UFRGS. Professora do Programa de Pós Graduação em Ensino - UNIVATES e Programa de Pós Graduação em Ensino de Ciências Exatas - UNIVATES. E-mail: jacqueh@univates.br Orcid: https://orcid.org/0000-0001-7199-4047 
involucramiento de los niños en las propuestas investigativas permite la constitución de una imagen más adecuada de la epistemología del conocimiento, además de darse cuenta de la inexistencia de una jerarquía axiológica entre las diferentes formas de conocimiento. Se entiende que el desarrollo de estas habilidades es una condición importante para la adopción de una postura ética y dialógica en relación a la sociedad, así como el reconocimiento de la incertidumbre y su propia incompletitud.

Palabras-clave: Enseñanza por Investigación. La Humildad Intelectual. Epistemología. Principio Moral. Enseñanza de la Ciencia

\section{INTRODUÇÃO}

Propor uma discussão acerca do conceito de humildade como um objetivo para a educação escolar pode soar como uma ambiguidade, tendo em vista que se vive em um contexto histórico e cultural marcado por um esforço deliberado para otimizar e acelerar quantitativamente as aprendizagens formais das crianças (DAHLBERG; MOSS; PENCE, 2019). Por sua vez, o conceito de humildade, coloquialmente, é associado a um adjetivo negativo, caracterizando alguém que "é menos". No entanto, na perspectiva crítica, adotada neste estudo, a humildade intelectual é compreendida como uma virtude necessária para a vida em sociedade e para 0 aprendizado contínuo (REDIN, 2010; FREIRE, 2011a; ECC0, 2015).

Optou-se por apontar a humildade intelectual como um objetivo emergente, pois entende-se que ela é uma necessidade em um contexto contemporâneo, no qual observa-se uma postura cética e depreciativa com os saberes que não são constituintes do sujeito epistêmico. Soma-se a isso, a crescente tensão existente entre grupos ideologicamente distintos que não se dispõem ao diálogo, bem como a aceleração da racionalização das relações humanas (SCHUCK, LORENZON, 2017). Assim, a humildade intelectual e as demais virtudes adjacentes a ela, como o respeito e a disponibilidade de escuta, passam a ser pressupostos éticos necessários para a vida em sociedade.

As virtudes, entendidas como valores necessários para a criação de uma sociedade justa e respeitosa, não são inatas aos indivíduos, nem podem ser transmitidas ou internalizadas de modo mecânico. Antes de tudo, elas decorrem de um ambiente que atua de modo formador. Brito (2015) enfatiza que em uma sociedade institucionalizada, como a atual, é fundamental que a formação das virtudes humanas seja uma das dimensões contempladas nos projetos pedagógicos. Para tanto, segundo o autor, é fundamental repensar os múltiplos aspectos que envolvem os processos de ensino e aprendizagem, tais como as estratégias de ensino, as relações discente e docente e a organização arquitetônica.

Neste estudo, dá-se ênfase às estratégias de ensino e as suas relações com o processo de desenvolvimento da virtude da humildade intelectual. Pressupõe-se que as abordagens de ensino marcadas pela instrução e que compreendem o conhecimento escolar como doxa, não atendem a estas demandas, por reforçarem uma postura dogmática frente ao conhecimento (FREIRE, 2011b). Além disto, por pensar o educando como um receptor de informações, essa forma de ensinar não o compreende como um sujeito-epistêmico, isto é, alguém que não só sabe, mas é constituído por saberes (LEERNER, 2012).

As propostas de ensino baseadas no treino e na instrução fomentam um processo de ruptura subjetiva que pode desencadear, tanto na desumanização do sujeito (FREIRE, 2011a), como pode reforçar uma postura de ceticismo e desconfiança total ao novo conhecimento que está sendo transmitido. Mesmo que os resultados sejam paradoxalmente diferentes, ambos convergem ao não 
possibilitar 0 desenvolvimento da virtude da humildade intelectual. A desumanização, intimamente associada a um saber-regulação (SANTOS, 2011), promove o silenciamento do indivíduo e 0 leva a construir uma autopercepção negativa de nada saber ou que seus conhecimentos não possuem valor formal. Por outro lado, a desconfiança e o ceticismo absoluto passam a negar a existência de formas de saber distintas da sua, o que impossibilita o diálogo.

A virtude da humildade intelectual pressupõe a não submissão, mas também perceber a falibilidade do seu modo de compreender o mundo, as limitações do próprio conhecimento e o reconhecimento do outro como fonte de aprendizagem (REDIN, 2010). Para que isso ocorra, é necessário 0 empenho em busca de pedagogias orgânicas e relacionais, que reconheçam a multidimensionalidade destes sujeitos-epistêmicos e a inexistência de uma hierarquia entre as diferentes formas de saber. Pensa-se que as propostas de ensino que promovem a investigação, por contemplar os aspectos supracitados, são um caminho possível para o desenvolvimento desta virtude. Neste viés, o objetivo deste estudo é discutir as possibilidades de uma abordagem de ensino investigativa fomentar o desenvolvimento da humildade intelectual de crianças nos Anos Iniciais do Ensino Fundamental. Os pressupostos teóricos da pesquisa provêm de uma aproximação entre o pensamento crítico (REDIN, 2010; SANTOS, 2011; FREIRE, 2011a, 2011b; ECCO, 2015) e as Pedagogias das Infâncias (SILVA, 2011; MALAGUZZI, 2016; OLIVEIRA-FORMOSINHO; FORMOSINHO, 2019; HOYUELOS, 2020).

0 artigo encontra-se organizado em quatro seções. Na primeira delas, intitulada Humildade Intelectual: Um conceito emergente, discute-se o conceito de humildade intelectual e a sua interface com as estratégias de ensino utilizadas nos Anos Iniciais do Ensino Fundamental. Na seção Desenho de Pesquisa: Uma proposta metodológica descreve-se a metodologia da pesquisa, o contexto em que o estudo foi realizado, os instrumentos para a produção do corpus e a técnica de análise de dados. As contribuições das propostas de Ensino por Investigação para o desenvolvimento da humildade intelectual discutida são apresentadas na seção Abordagens Investigativas e 0 desenvolvimento de habilidades epistemológicas. Finaliza-se 0 artigo propondo alguns princípios de trabalho que podem ser pertinentes para pensar uma prática pedagógica voltada para o desenvolvimento de um modo de ser condizente com as necessidades contemporâneas.

\section{HUMILDADE INTELECTUAL: UM CONCEITO EMERGENTE}

Na perspectiva da pedagogia crítica, a humildade intelectual não é definida como uma habilidade ou competência, mas sim como uma virtude (FREIRE, 2011a; ECCO, 2015). Uma virtude, conforme Ecco (2015, p. 174), é entendida como um "[...] valor necessário para a construção de uma sociedade mais humana". 0 autor, ao tratar da relação docente-discente, destaca que a amorosidade, a coerência, a confiança, a curiosidade, a decência, a dialogicidade, o escutar, a esperança, a humildade, o respeito, a simplicidade e a tolerância são virtudes essenciais para pensar uma educação e uma sociedade humanizadora. Por sua vez, Brito (2015) corrobora com esta perspectiva ao indicar que as virtudes são qualidades desejáveis e necessárias para a convivência social. Assim, a existência de uma sociedade ética e que garanta bem estar e segurança física e emocional dos seus membros requer atitudes virtuosas.

As virtudes, dado o seu caráter complexo, não são inatas aos seres humanos, nem sequer resultados de períodos de treino e instrução. 0 indivíduo virtuoso emerge de uma intrincada rede de relações, nas quais incidem aspectos de ordem biológica, cultural e social. Desta forma, o desenvolvimento das virtudes poderia ser configurado como uma aprendizagem cotidiana que nem sempre 
ocorre de modo intencional ou consciente, mas "é informal, implícita, incidente, da ordem da socialização ou da aculturação" (BROUGÈRE, 2012, p. 15). No entanto, Brito (2015) salienta que, pelo fato da sociedade contemporânea ser fortemente institucionalizada, é fundamental que as instituições educativas assumam, conscientemente, o objetivo de fomentar o desenvolvimento destes valores.

Conforme apresentado anteriormente, há inúmeros valores considerados essenciais para a vida em sociedade, sendo que cada um deles traz implicações diversas para o desenvolvimento de práticas pedagógicas (ECCO, 2015). Dada a complexidade de abarcar todos em um único texto, neste estudo dá-se ênfase à humildade intelectual, pois ela está intimamente associada às práticas e às estratégias de ensino.

A humildade, afirma Redin (2010), vulgarmente, foi associada a um adjetivo negativo, sendo, muitas vezes, pensada como sinônimo de fraqueza, pobreza e submissão, e resultando em um "[...] comportamento de autodesprezo, insignificância, baixa autoestima, quase vergonha” (REDIN, 2010, p. 212). Na tradição pedagógica, Freire (2011a) rompe com esta perspectiva ao apontar que ser humilde é reconhecer a finitude do seu próprio saber e, consequentemente, respeitar, escutar e dialogar com o outro, compreendendo-o como um parceiro fundamental para as suas próprias aprendizagens.

Desta forma, a humildade contemplaria duas dimensões. A primeira abarca a relação do indivíduo consigo, possibilitando que ele seja capaz de reconhecer a relevância dos seus conhecimentos, mesmo que não sejam oriundos das ciências formais. A dimensão individual contemplaria ainda, 0 reconhecimento que a sua forma de compreender o mundo é finita e contextual. Reconhecer a validade epistemológica dos seus saberes é condição essencial para os processos de humanização, tendo em vista que renunciar o seu conhecimento ou não o perceber como válido significa romper consigo mesmo (LEENER, 2012). Em contrapartida, assumi-lo como absoluto também é um impeditivo para a aprendizagem, pois encerraria as possibilidades de diálogo e, consequentemente, a oportunidade de construir novos sentidos sobre o mundo (GADAMER, 2004; LORENZON, SCHUCK, 2017). Assim, a humildade intelectual exige uma postura de perceber que "o que ignoramos é sempre a ignorância de uma certa forma de conhecimento e vive-versa o que conhecemos é sempre o conhecimento em relação a uma certa forma de ignorância" (SANTOS, 2011, 29).

A segunda dimensão da humildade intelectual apresenta um cunho social, abarcando as relações do indivíduo com os demais integrantes da sociedade. Como exposto anteriormente, uma postura de humildade intelectual implica reconhecer e adotar uma perspectiva responsiva com os outros, reconhecendo-os como fundamentais para a ocorrência de relações dialógicas e, consequentemente, a aprendizagem (GADAMER, 2004; LORENZON, SCHUCK, 2017). Ecco (2015) complementa essa perspectiva afirmando que a humildade requer uma "[...] atitude e um comportamento legítimo, autêntico e coerente de respeito, de apreço, de promoção do outro” (ECC0, 2015, p. 181).

Frente ao exposto, entende-se que o indivíduo intelectualmente humilde conseguirá estabelecer uma relação mais positiva consigo por reconhecer a validade epistemológica do seu conhecimento e também adotará uma postura de escuta e diálogo com os outros. Reitera-se que o desenvolvimento desta virtude requer um empreendimento consciente por parte das instituições. Em relação às escolas, Brito (2015) enfatiza a necessidade de uma reflexão ampla que inclui:

[...] desde a concepção das salas de aula, à relação com os docentes, os pais dele e deles entre si, ao modo como a aprendizagem tem de acontecer na interação com os demais e, finalmente, ao modo como o lúdico tem de ser incorporado à vida escolar. A socialização não pode, se queremos formar pessoas melhores e que podem ser 
capazes de viver melhor, estar baseada no adestramento dos indivíduos para que possam aprender a seguir regras, mas na sua introdução a um meio no qual a vida coletiva esteja no centro e desperte e exercite nele as inclinações do animal social que somos (BRIT0, 2015, p. 169).

A experiência de vida em comunidade, baseada no diálogo, na ética, na escuta e no respeito mútuo não pode ser alcançada por meio de pedagogias que enfatizem o treino e a instrução (FORMOSINHO; OLIVEIRA-FORMOSINHO, 2019a, 2019b). Uma abordagem pedagógica voltada para o desenvolvimento da humildade intelectual torna necessário a adoção de um outro paradigma pedagógico, fundados na participação, no reconhecimento dos estudantes como sujeitos de direitos e que aborde 0 conhecimento de modo holístico e complexo (HOYUELOS, 2020; FORMOSINHO; OLIVEIRA-FORMOSINHO, 2019a). É neste contexto que as abordagens de ensino investigativas podem corroborar significativamente para 0 desenvolvimento de uma proposta pedagógica voltada para a formação integral das crianças e para a promoção da virtude da humildade intelectual.

\section{DESENHO DE PESQUISA: UMA PROPOSTA METODOLÓGICA}

Este artigo é um desdobramento de uma pesquisa intitulada "A Espiral Investigativa como uma Estratégia de desenvolvimento da Alfabetização Científica nos Anos Iniciais", desenvolvida enquanto discente em um Programa de Pós Graduação, a nível de mestrado, de uma universidade localizada no interior do estado do Rio Grande do Sul. A pesquisa caracterizou-se por uma abordagem qualitativa em que um dos autores, ao emergirem no campo de estudo, tornaram-se a principal fonte de dados. A escolha por essa abordagem decorre do entendimento que as investigações qualitativas são mais adequadas quando espera-se analisar a ocorrência de um fenômeno em seu contexto de ocorrência natural, analisando todas as nuances envolvidas em seu processo de ocorrência (BIKLEN, BOGDAN, 1994).

Tendo em vista que, conforme Biklen e Bogdan (1994), a abordagem qualitativa é um termo genérico que abarca um rol bastante amplo e heterogêneo de tipos de pesquisa, optou-se por desenvolver um estudo que aproxima-se da Investigação Pedagógica (RINALDI, 2016) e contempla alguns princípios da Pesquisa-Ação (THIOLLENT, 2004). Rinaldi (2016) define a Investigação Pedagógica como um empreendimento que o docente realiza de investigar a sua prática pedagógica, buscando registrar e analisar episódios cotidianos, confrontando-os com pressupostos teóricos da ciências da educação, a fim de desenvolver novos entendimentos sobre o próprio fazer pedagógico. Assim, a Investigação Pedagógica é um tipo de pesquisa que envolve planejar situações de aprendizagens, aplicá-las, documentá-las, refletir sobre os resultados obtidos e, a partir das inferências, retroalimentar o seu planejamento. dida como

Resguardada as diferenças, a Investigação Pedagógica se aproxima da pesquisa-ação enten-

[...] um tipo de pesquisa social com base empírica que é concebida e realizada em estreita associação com uma ação ou com a resolução de um problema coletivo e no qual os pesquisadores e os participantes representativos da situação ou do problema estão envolvidos de modo cooperativo ou participativo (THIOLLENT, 2004, p. 14).

Neste viés, tanto nas Investigações Pedagógicas, como na Pesquisa-Ação, existe apenas uma tênue separação entre pesquisador e os participantes da pesquisa, sendo que ambos desempenham 
"[...] um papel ativo na própria realidade" (THIOLLENT, 2004, p. 16). Além disso, ambas as pesquisas envolvem um esforço cooperativo para transformar e qualificar a realidade (RINALDI, 2016; RIERA, 2019; THIOLLENT, 2004).

A opção por desenvolver um estudo com esta caracterização, decorre do fato que um dos pesquisadores era professor de uma turma de $3^{\circ}$ Ano do Ensino Fundamental em uma escola da rede pública de ensino de Arroio do Meio/RS. As crianças que frequentavam esta turma já estavam familiarizadas com situações de aprendizagem que apresentavam um caráter investigativo e a presença de um docente-pesquisador permitiria registrar de modo integral e permanente 0 envolvimento dos estudantes com as atividades propostas e documentar o desenvolvimento de novas habilidades. Assim, participaram do estudo 25 crianças com idade entre 8 e 9 anos. Seguindo-se os pressupostos da Sociologia da Infância, optou-se por identificar nominalmente as crianças participantes do estudo.

0 corpus da pesquisa foi produzido por meio de observações registradas em um Diário de Itinerância, Registros Fotográficos, entrevistas semiestruturadas com as crianças e análise da Documentação Pedagógica (Diário de Aula, Reflexões do Docente e produções das crianças). 0 Diário de Itinerância pode ser definido como um "[...] bloco de apontamentos no qual cada pesquisador anota 0 que sente, 0 que medita, 0 que poetiza, o que retém de uma teoria, de uma conversa, o que constrói para dar sentido a sua vida" (BARBIER, 2004, p. 113). Logo, este diário é um registro do próprio percurso estrutural da investigação (SILVA, 2011).

Dado 0 fato da presença do docente-pesquisador e da existência de um envolvimento colaborativo com as crianças, os registros fotográficos foram produzidos por todos os participantes da pesquisa. Para tanto, foram disponibilizadas câmeras fotográficas na sala de aula e as crianças foram instruídas sobre como utilizá-las para realizar registros de situações que consideravam pertinentes. Este instrumento de pesquisa permitiu a produção de um inventário amplo de objetos e rituais ocorridos em sala de aula que, posteriormente, puderam ser utilizados para ilustrar episódios descritos ou gerar novos insights nos pesquisadores.

Ao final da pesquisa de campo foram realizadas entrevistas semiestruturadas com as 25 crianças. Neste momento, os pesquisadores propuseram algumas questões abertas que resultaram em diálogos nas quais as crianças relataram situações vivenciadas ao longo da pesquisa e refletiram sobre as suas aprendizagens no período. Com intuito de registrar conversas não intencionais entre os participantes, no decorrer da estadia em campo foram disponibilizados gravadores de áudio que foram utilizados pelos estudantes para registrar situações espontâneas e trabalhos desenvolvidos de modo coletivo. As gravações resultantes dessas intervenções e das entrevistas foram transcritas e analisadas pelos pesquisadores.

Em complemento aos instrumentos supracitados, realizou-se a análise da documentação pedagógica, entendida como um conjunto de registros e produções decorrentes das práticas pedagógicas. Desta forma, analisou-se os Diário de Aula do docente, em que estavam descritas as situações de aprendizagem realizadas ao longo do ano letivo, bem como os objetivos, justificativas para os projetos, relatos de episódios vivenciados e avaliação das propostas. Além disso, foram analisadas produções que as crianças realizaram (desenhos, narrativas, folhas de exercício) e os Diários Individuais que cada criança manteve naquele ano letivo e que registravam as suas aprendizagens.

Os dados do estudo foram analisados por meio da técnica da Análise Textual Discursiva que, segundo Moraes e Galiazzi (2011), consiste em um conjunto de procedimentos que tem a intenção de permitir ao pesquisador reconstruir e interpretar as situações registradas. Ainda, em conformidade 
com os autores, este procedimento de análise e interpretação contempla três etapas sequenciais: unitarização, categorização e captura dos emergentes.

A etapa da unitarização consiste na realização de uma leitura atenta dos materiais produzidos no decorrer da pesquisa de campo, selecionando episódios que respondem aos questionamentos da investigação. Moraes e Galiazzi (2011) afirmam que esta etapa é essencial, tendo em vista a impossibilidade de trabalhar de modo atento e detalhado com todo corpus de pesquisa.

No processo de unitarização, os pesquisadores constituem unidades de análise que, quando lidas de modo separado, apresentam sentido. Na etapa de categorização, as unidades de análise são agrupadas conforme as semelhanças que possuem, criando assim as categorias (MORAES, GALIAZZI, 2011). Neste estudo, optou-se por uma categorização indutiva em que os critérios subjacentes a cada agrupamento de unidades foram elaborados a partir da leitura do material constituinte do corpus, não existindo assim de modo prévio (MORAES, GALIAZZI, 2011).

Ao final da etapa de categorização, foram mantidas apenas as categorias que contemplavam unidades de análise produzidas a partir de diferentes instrumentos, buscando assim garantir a cientificidade do estudo por meio da triangulação de informações (CARVALHO, 2007). A terceira etapa da Análise Textual Discursiva consiste na captura dos emergentes, em que ocorrem as novas compreensões dos materiais coletados (MORAES, 2011). Neste momento, ocorreu a confrontação entre os dados empíricos e marcos teóricos, a fim de obter novos sentidos (RIERA, 2019).

0 estabelecimento dos parâmetros de ética em pesquisa seguiu os critérios estabelecidos pela Resolução 510/2016 do Conselho Nacional de Saúde (BRASIL, 2016) e alguns pressupostos da sociologia e da antropologia da infância (CORSAR0, 2011; FRIEDMANN, 2020). Primeiramente, como a pesquisa foi realizada em uma instituição de ensino, foi firmado um Termo de Anuência com os gestores responsáveis, no qual foram expostas as intencionalidades do estudo, bem como os direitos e deveres das partes envolvidas.

Na sequência, foram encaminhados Termos de Consentimento Livre e Esclarecido para os responsáveis legais das crianças, a fim de obter a anuência para sua participação no estudo. Por meio deste documento, que se encontra assinado e arquivado, foram esclarecidos objetivos e métodos de pesquisa e solicitado a autorização para realizar registros das crianças e análise de suas produções, bem como utilizar o material coletado para as produções decorrentes do estudo.

Uma vez que na perspectiva teórica empregada as crianças são compreendidas como sujeitos de direito, elas foram comunicadas acerca da pesquisa que seria realizada e foram convidadas, por meio de um diálogo, a participar (FRIEDMANN, 2020). Além disso, o entendimento que as crianças são atores sociais, não podendo ser universalizadas ou ocultas em uma multidão anônima (CORSARO, 2011), fez com que se optasse por identificá-las nominalmente e apresentar seus rostos em registros fotográficos. Este entendimento foi apresentado aos gestores da instituição em que o estudo foi realizado, aos responsáveis legais das crianças e às crianças, sendo consentida e registrada por escrito.

\section{ABORDAGENS INVESTIGATIVAS E 0 DESENVOLVIMENTO DE HABILIDADES EPISTEMOLÓGICAS}

Nesta seção do artigo, discute-se, a partir de episódios documentados, de que modo uma abordagem de ensino investigativa pode auxiliar a constituir um sujeito dotado de humildade intelectual. No contexto estudado, a proposta de Ensino por Investigação ocorria por meio do envolvimento das crianças em uma Espiral Investigativa que, conforme Lorenzon (2018, p. 37), pode ser definida como "[...] um conjunto de situações de aprendizagem que permitem às crianças um estudo aprofundado 
sobre determinados temas". Assim, esta proposta de trabalho é bastante flexível, podendo contemplar um rol bastante amplo e heterogêneo de situações de aprendizagens.

As situações de aprendizagem propostas em uma Espiral Investigativa podem ser organizadas em quatro etapas: elaboração de questionamentos, formulação de hipóteses, construção de argumentos e comunicação dos achados. A primeira etapa contempla a escuta do docente para identificar temas de interesse ou necessidade das crianças, momento de expor os conhecimentos prévios dos participantes sobre o tema, estratégias de identificação de lacunas nas informações explanadas e, por fim, a elaboração de perguntas orientadoras da investigação.

Entende-se que 0 ato de escutar e contemplar temas de interesse das crianças na Espiral Investigativa são princípios éticos (HOYUELOS, 2020), além de recursos que permitem a construção de um ambiente respeitoso, democrático e propenso a participação (SILVA, 2011; FORMOSINHO, OLIVEIRA-FORMOSINHO, 2019; DEWEY, 1979; MURARO, 2019). Soma-se a isso, que ao contemplar no currículo escolar temas familiares às crianças, possibilita-se a criação de espaços participativos em que elas auxiliam ativamente na organização do planejamento pedagógico, sendo propositivas em relação a algumas possibilidades de trabalho (KATZ, 2016). A identificação de temas ou tópicos que darão origem às investigações é sucedida por um momento que os participantes expõem seus conhecimentos sobre o tema, explicitando, de forma oral ou escrita, suas suposições e entendimentos. A partir dessa identificação daquilo que elas já conhecem, inicia-se um esforço de identificar lacunas ou possibilidades de ampliar o conhecimento existente (BIZZO, 2001; LIVIO, 2018) e, por fim, elabora-se alguns questionamentos que serão respondidos no decorrer da Espiral Investigativa.

A segunda etapa da Espiral Investigativa agrupa situações de aprendizagem que levam à formulação de hipóteses aos questionamentos elaborados antecipadamente. As hipóteses são entendidas como uma "paragem provisória do pensamento" (CACHAPUZ et al, 2005, p. 92), isto é, uma suposição ou uma resposta possível formulada a partir daquilo que se sabe naquele momento. Lorenzon (2018, p. 39) identifica que as "suposições acabam agindo como condicionantes de uma investigação, pois é a partir dessas asserções que são construídas situações que permitam identificar a sua plausibilidade". Nota-se assim que a proposta é emergente ou uma projetação, nas quais as etapas e situações de aprendizagem que irão ocorrer estão intimamente associadas aos acontecimentos, falas e sugestões das crianças.

A partir do momento que as crianças elaboram as suas hipóteses, inicia-se um processo colaborativo de construção de argumentos para sustentá-las ou de reunir evidências que levam à sua refutação. A etapa de Construção de Argumentos é o momento em que os participantes empreendem um esforço para reunir informações, produzir e analisar dados, bem como organizá-los, categorizá-los e articulá-los de modo a sustentarem as suas afirmações. Neste momento ocorrem situações de aprendizagem diversas que envolvem a leitura e interpretação de textos, a análise de infográficos e documentários, entrevistas com membros da comunidade, saídas de estudo para espaços não-formais ou informais de ensino e organização de experimentos. 0 planejamento e a seleção das estratégias mais adequadas para o momento ficará à critério do docente e está condicionada ao tema que está sendo investigado e aos questionamentos formulados pelos estudantes.

Por fim, após a organização das informações, inicia-se a etapa de comunicação dos achados de investigação, em que as crianças produzem artefatos, isto é, itens que representam suas aprendizagens e as respostas aos questionamentos iniciais (BENDER, 2014). Assim, são produzidos maquetes, modelos, textos escritos ou recursos digitais que tornam visíveis as aprendizagens e são utilizados para comunicá-las aos demais membros da comunidade escolar. Lorenzon (2018) afirma 
que neste momento é comum surgirem novas perguntas sobre o tema que está sendo apresentado que, muitas vezes, desencadeiam em novas investigações. Desta forma, a Espiral Investigativa possui um caráter generativo de novas investigações.

Salienta-se ainda que as propostas de investigações decorrentes da Espiral Investigativa podem ser empreendidas por toda turma, mas também por pequenos grupos que trabalham em paralelo e abordam temas distintos. Neste estudo, observou-se, predominantemente, o trabalho em pequenos grupos.

Dada essa apresentação acerca do modo de organização do trabalho pedagógico, apresenta-se agora os dados que foram produzidos no decorrer da pesquisa de campo. Estes, foram dispostos em três categorias que abordam, respectivamente, a valorização de saberes do contexto social; a percepção do conhecimento como uma produção humana e o reconhecimento dos próprios processos cognitivos.

Na primeira categoria, apresentam-se episódios que explicitam a possibilidade de uma abordagem investigativa fomentar a valorização de saberes do contexto social, Quando se propõem a escutar as crianças, abrem-se possibilidades de seu cotidiano e de suas vivências serem contempladas no currículo escolar. Questionamentos acerca das interações sociais e eventos de sua realidade imediata passam a tornar-se frequentes e, muitas vezes, as respostas e explicações a eles não são encontradas nos suportes usuais de informação, como livros e documentários. Assim, torna-se necessário realizar um empreendimento de trazer à escola pessoas da comunidade ou ir até elas.

No decorrer da pesquisa de campo, situações como essa ocorreram em projetos, tais como "A tração dos veículos 4 × 4", "Um lugar especial: Histórias do nosso bairro", "Os elementos químicos nos chocolates" e "Atividades econômicas do Bairro Bela Vista". Na primeira investigação, um pequeno grupo de crianças se propôs a estudar os veículos utilizados para realização de trilhas e, entre os questionamentos elencados, estavam dois sobre o funcionamento da suspensão e da tração destes veículos. Tendo em vista que as crianças e o professor não encontraram recursos que atendiam de modo satisfatório as dúvidas, um dos integrantes propôs a realização de uma visita à oficina mecânica de seu pai. Nesta visita, as crianças puderam conversar com um profissional sobre 0 assunto e observar peças dos veículos. No retorno à sala de aula, as crianças, além de elencar suas aprendizagens, expuseram a satisfação de poder visitar um espaço pertencente ao familiar de um de seus colegas.

No projeto "Um Iugar especial: Histórias do nosso bairro", as crianças elencaram como questionamentos para sua investigação, fatos bem específicos e peculiares sobre a vida na comunidade, tais como os modos de se vestir, atividades de lazer e o interior das casas antigas (Caderno da aluna Natália Luísa Feil). A fim de responder aos questionamentos, foi convidado um membro da comunidade local para conversar com as crianças e responder aos seus questionamentos.

As entrevistas com membros da comunidade também foram realizadas na investigação "Os elementos químicos nos chocolates" em que as crianças buscavam saber do que o chocolate era composto e 0 que significava os nomes dos ingredientes contidos nas embalagens. Para responder a este questionamento, 0 docente convidou a nutricionista para falar sobre 0 tema. Além disso, 0 aluno João Vitor (9 anos) gravou uma entrevista com um familiar que trabalhava em uma fábrica de chocolates. Posteriormente, o material foi ouvido e discutido por um pequeno grupo de crianças que estavam mais envolvidas com a temática.

Por fim, na investigação "Atividades econômicas do Bairro Bela Vista" realizou-se uma visita à uma fábrica de calçados e entrevista com funcionários que trabalhavam neste local. 0 objetivo desta 
visita, além de conhecer o funcionamento de uma indústria, tinha como finalidade valorizar a profissão dos familiares das crianças, tendo em vista que muitas manifestavam vergonha do emprego de seus pais (Diário de Itinerância).

Figura 1 - Saídas de Estudo como estratégia de valorização de saberes locais

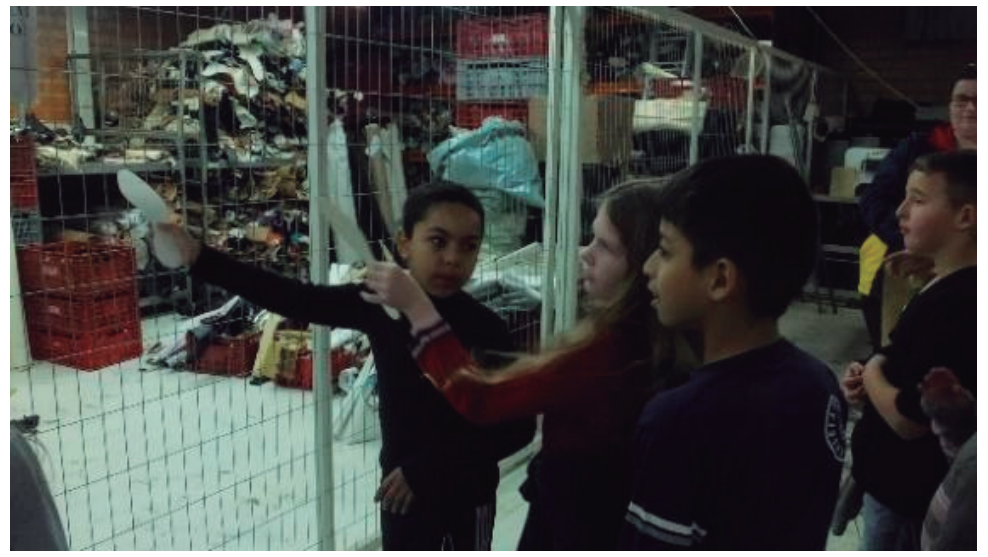

Fonte: Acervo de Pesquisa

Entende-se que contemplar no currículo escolar situações que envolvem investigar o próprio meio e escutar os membros da comunidade é uma forma de valorizar saberes locais, reconhecendo-os como um mentefato possível de ser utilizado para a leitura do mundo (CHASSOT, 2014). Não se trata assim de estabelecer uma hierarquia entre diferentes modos de compreender o mundo, mas "reconhecer o saber popular, não como uma ameaça [à ciência], mas como um espelho que reflete as limitações do saber científico" (LORENZON, OLIVEIRA, DEL PINO, 2020, p. 218).

Diante disso, pensa-se que a adoção de uma pedagogia aberta ao meio, leva a construção de uma relação positiva com os saberes e fazeres cotidianos, além de dar voz aos indivíduos historicamente excluídos ou silenciados (LORENZON, SILVA, 2020; SANTOS, 2011). A presença desse "outro" no currículo escolar possibilita a legitimação de sua voz, abrindo assim possibilidades de uma ação dialógica, que é um indicativo da humildade intelectual. Desta forma, se supõe que a humildade intelectual requer perceber que o conhecimento é sempre incompleto e que os membros da comunidade, independente da sua escolarização ou posição social, possuem algo a ensinar.

A segunda categoria trata das possibilidades do envolvimento em investigação auxiliar os estudantes a perceber o conhecimento científico como uma produção humana. Uma das características do conhecimento que circula no ambiente escolar é a sua impessoalidade. Os livros didáticos utilizados, muitas vezes, apresentam os fatos de modo dogmático e como algo ahistórico, sem relatar os contextos em que aquelas informações foram produzidas (CHASSOT, 2014). As pedagogias bancárias reforçam essa suposição, por narrarem e descreverem os fenômenos de modo que eles pareçam ser transcendentes à humanidade (FREIRE, 2011b). Tal situação, pode conduzir ao estabelecimento de uma hierarquia axiológica em que há um ceticismo absoluto ou uma confiança ingênua.

A ingenuidade em relação à produção do conhecimento científico, pode ser observada, por exemplo, em um grupo de crianças que estudava "Explorações Espaciais: A sonda Curiosity". Naquela ocasião as crianças, o grupo discutia sobre o custo de fazer uma viagem espacial e, surpre- 
sos com os valores, queriam entender o porquê de elas serem realizadas. 0 professor se aproxima e explica que as sondas serviam para coletar informações sobre o planeta. Uma das crianças que observava a conversa aproxima-se e pergunta “Mas não era mais fácil procurar no Google?” (Diário de Itinerância). Esta situação revela uma postura dogmática do conhecimento, que pode ser explicada pelo contexto contemporâneo em que as informações são abundantes e difusas (SERRES, 2013). Essa situação faz com que pouco reflita sobre a epistemologia das informações lidas ou ouvidas.

Pressupõe-se que romper com essas percepções dogmáticas acerca do conhecimento é uma condição essencial para adoção de uma postura de humildade. Entende-se que as abordagens investigativas permitem a relação crítica com 0 conhecimento por envolverem as crianças em processos de produção e análise de dados, bem como apresentar a elas a história da ciência.

Em decorrência da investigação "Os elementos químicos nos chocolates", o grupo de crianças, a partir da entrevista relatada anteriormente, queria saber como as barras de chocolate mantinham-se em estado sólido. 0 relato abaixo foi produzido a partir da transcrição de uma gravação de áudio esporádica:

O grupo de crianças estava reunido e surgiu a questão do porquê e como os chocolates mantinham-se sólidos. João Vitor lembrou que na entrevista que realizou, seu familiar falava a respeito da existência de grandes geladeiras nas fábricas que resfriavam os chocolates. A princípio, os demais aceitaram a suposição, mas com o prosseguimento da conversa lembraram que no mercado as barras de chocolate não estavam em geladeiras, mas sim nas prateleiras. Com isso, as crianças formularam a hipótese de que em uma determinada temperatura o chocolate derreteria. Para descobri-la, as crianças formularam um experimento em que deixariam pedaços de chocolate no sol junto com um termômetro, a fim de observar que temperatura estaria quando ela começasse a derreter (Notas do Diário de Itinerância, anotações em relação a gravação de áudio).

No episódio relatado, percebe-se que o experimento proposto pelas crianças não é concebido como um recurso aleatório, mas sim como uma necessidade para resolver um conflito existente por uma informação nova em sua estrutura mental (FERREIRA, 2003). Situações como a descrita auxiliam os estudantes a perceberem que a ciência não pode ser reduzida a processos experimentais aleatórios, isto é, uma visão puramente empirista (CACHAPUZ et al, 2005).

Figura 2 - Crianças realizando uma atividade experimental

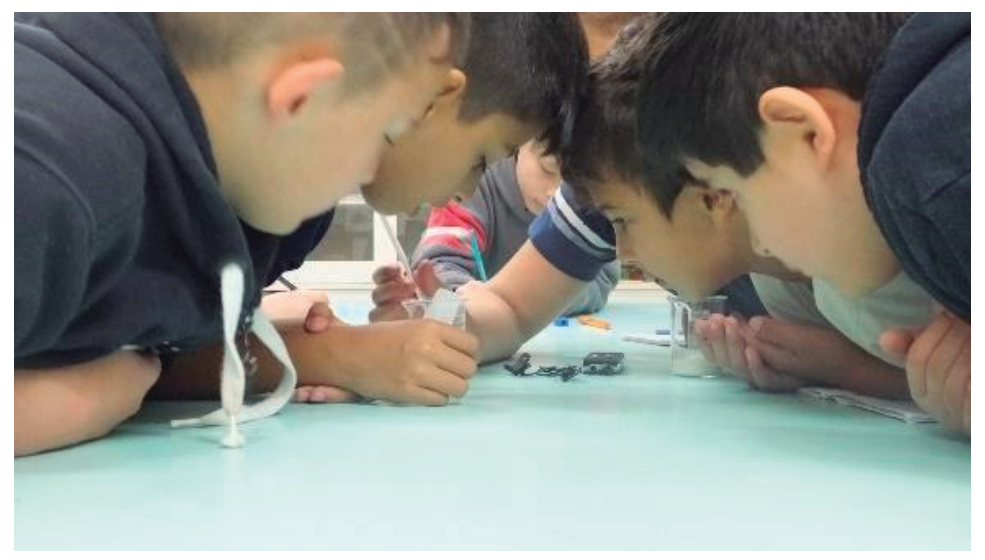

Fonte: Acervo de Pesquisa 
A percepção do caráter humano das ciências também pode ser fomentada por meio do trabalho com biografias de grandes personalidades da ciência, em especial, sobre seus relatos da ciência. 0 projeto "Charles Darwin: A Infância de um grande cientista" exemplifica esta situação, pois por meio da leitura de uma biografia adaptada às crianças conseguiram percebê-lo como uma figura humana, dotada de dúvidas, anseios e alegrias, rompendo assim com as imagens estereotipadas do cientista (BUSKE, SANTOS, TEMP, 2015). No entanto, a leitura que parece ter desencadeado maior reflexão por parte das crianças foi a biografia de Marie Curie em decorrência de uma investigação sobre os "Elementos Químicos". Após este estudo, Natália relatou em entrevista que "ela teve uma história muito triste, que o marido dela sofreu um acidente com cavalos e ela ficou solitária. Mas ela não desistiu e continuou os estudos" (Transcrição de Entrevista). Em seu diário, a mesma aluna anotou ainda que "Marie Curie incentivou as mulheres a serem protagonistas" (Diário Individual). A mesma perspectiva é reforçada por Fernanda que, em entrevista, quando questionada sobre as aprendizagens do semestre afirmou:

Eu lembro da Marie Curie. Era era uma mulher que perdeu o marido, mas ela estudava as coisas com o marido. Ela foi a primeira mulher a ganhar dois Prêmios Nobel. Antes dela, as mulheres eram para cuidar dos bebês, varrer a casa e daí ela ganhou um Nobel por ser corajosa. Ela disse que as mulheres não serviam só para isso (Transcrição de Entrevista).

Perceber que o conhecimento científico é resultado de interpretações, bem como conhecer histórias de homens e mulheres que estão envolvidos em processos de pesquisa ou são grandes personalidades das ciências, são condições importantes para o desenvolvimento de uma visão coerente da epistemologia das ciências. Ao desenvolver essa percepção, as crianças poderiam reforçar 0 entendimento que a ciência é uma das possibilidades de leitura do mundo que coexistem com os outros mentefatos (CHASSOT, 2014).

A reflexão epistemológica, decorrente da percepção que o conhecimento científico não é absoluto, permite um processo de humanização do indivíduo (LORENZON, 2020). Para tanto, Lorenzon, Oliveira e Del Pino (2020, p. 218) afirma que é necessário optar por estratégias de ensino que não apresentem "[...]o conhecimento científico como doxa, mas sim como uma forma de compreender 0 mundo produzido por uma racionalidade (episteme) própria e que pode coexistir com outras leituras de mundo, sem que uma anule o/a outro/a". Diante disso, se supõe que a adoção de uma postura de Humildade Intelectual implica em perceber que há múltiplas formas de conhecimento e elas não se sobrepõem ou anulam-se, mas podem ser complementares.

Por fim, a terceira categoria trata das possibilidades da abordagem de ensino investigativa auxiliar as crianças a reconhecerem os seus próprios processos cognitivos. Supõe-se que a adoção de uma postura de humildade intelectual requer, além das habilidades apresentadas anteriormente, reconhecer e valorizar o que já se sabe sobre um determinado tema, perceber lacunas nas suas compreensões e ter confiança em sua própria capacidade de aprender. No decorrer da pesquisa, observou-se que as crianças desenvolvem estas habilidades, tanto nas vivências de investigação, como também por meio do manuseio dos instrumentos avaliativos que elas utilizam para registrar suas aprendizagens. No registro abaixo, extraído do Diário de Itinerância, observa-se a aluna Daniele fazendo reflexões sobre as suas aprendizagens: 
Faltam apenas duas semanas para o final do ano letivo e as crianças estão organizando a sala e guardando os trabalhos que fizeram. Daniele observa e folheia o seu Portfólio em que estão os registros dos projetos desenvolvidos ao longo do ano. Ao observar as perguntas de sua primeira investigação, ela olhou para os colegas e afirmou "Eu não acredito que eu tinha essa dúvida" (Notas do Diário de Itinerância, relato escrito a partir de uma filmagem).

Neste caso, observa-se que a criança, ao retomar o seu portfólio de aprendizagem pode observar as aprendizagens que construiu no decorrer do ano. Os questionamentos que ao final do ano letivo eram óbvios, no início do ano, eram questões pertinentes que a instigaram a investigar, isto é, foram questões gerativas que permitiram tornar seu conhecimento mais complexo. Tanto os Diários Individuais, como os Portfólios empregados como instrumentos avaliativos, fornecem oportunidades para as crianças, os professores e os familiares observarem um fluxograma das aprendizagens. Resnick (2020), ao discorrer sobre a complexidade da abordagem avaliativa, destaca a necessidade de instrumentos que deem ênfase processual, não restringindo-se a quantificações.

Além de permitirem acompanhar a trajetória das aprendizagens, as reflexões que as crianças fazem a partir dos registros podem servir como um elemento que fomenta a confiança em relação à sua capacidade de aprender. Assim, a documentação produzida constituiu uma base que garante segurança para os estudantes continuarem a explorar o mundo que os cerca.

0 último aspecto que se discute entre Espiral Investigativa e o desenvolvimento da postura de humildade intelectual é em relação ao questionar (-se). Trabalhar com abordagens de ensino investigativas pressupõe adotar um trabalho pedagógico que se baseia no exercício constante de dúvida e na escuta. As dúvidas e os questionamentos são manifestações da curiosidade humana.

A curiosidade sistêmica, isto é, aquela voltada para ampliar o conhecimento de mundo, é, segundo Lívio (2018), a condição que nos distingue dos demais animais. L'Ecuyer (2015) corrobora com essa perspectiva ao indicar que a curiosidade é um mecanismo natural e uma demonstração de um desejo de transcender a realidade imediata. Entende-se desta forma que ao perguntar o indivíduo explicita o reconhecimento de que ele é um sujeito incompleto. Ao mesmo tempo, é um convite ao diálogo e uma disponibilidade de escutar 0 outro.

Entende-se que a humildade intelectual consiste em um modo de ser que está em um processo contínuo de desenvolvimento. Ao vivenciarem e desenvolverem atividades de caráter investigativo, as crianças têm condições de valorizar saberes do seu contexto social, perceberem que a ciência não é um saber régio e absoluto e reconhecer seus próprios processos cognitivos, reconhecendo o que sabem e dispondo-se a continuar aprendendo.

\section{CONSIDERAÇÕES FINAIS}

Neste artigo discutiu-se o conceito de humildade intelectual e a sua necessidade em um contexto contemporâneo, no qual observa-se uma relação dogmática com o conhecimento, a impossibilidade do diálogo e a ausência de um sentimento de incompletude. A humildade intelectual foi discutida, não em uma perspectiva negativa de ser menos, mas sim como uma virtude necessária para a vida em sociedade e um indicador da percepção de sua própria incompletude e uma condição essencial para a ação consciente e para o diálogo. 
Ao discutir os processos de desenvolvimento da humildade intelectual nos estudantes, discorreu-se que, desde a mais tenra idade, é necessário que a criança seja protagonista em propostas que envolvam a construção do conhecimento. Entende-se que o envolvimento dela em situações de aprendizagens fundamentadas em uma proposta orgânica e sistêmica de aprendizagem, é essencial para o desenvolvimento de uma compreensão acerca da epistemologia dos diferentes saberes. Neste viés, atividades marcadas pelo treino, pela instrução e pela repetição mecânica não possibilitam 0 estabelecimento de uma visão crítica, visto que apresentam as informações de modo fechado, sem promover a reflexão acerca da sua natureza.

Conforme apresentado anteriormente, as situações de aprendizagem descritas decorreram de uma pesquisa realizada enquanto pesquisadores e docentes de uma turma de $3^{\circ}$ Ano do Ensino Fundamental. Reconhece-se que as práticas pedagógicas descritas não podem ser replicadas em sua integralidade em outros contextos, pois atendem um princípio de particularidade, isto é, são condicionadas a inúmeros fatores. No entanto, entende-se que elas podem ser extensíveis, ou seja, inspirar e oferecer subsídios para que outros docentes planejem práticas de caráter investigativo.

Longe de esgotar 0 assunto, propõe-se agora seis princípios que podem ser utilizados para pensar uma escola e uma educação para a humildade intelectual. 0 primeiro destes princípios é pensar em uma escola que trabalhe com demandas complexas, isto é, que os fenômenos sociais e locais tornem-se objetos de estudo. Assim, os conteúdos dariam lugar para situações reais que permitem perceber que nem sempre as soluções racionais são adequadas ou possíveis para a solução de problemas e das demandas. Nos Anos Iniciais do Ensino Fundamental, demandas corriqueiras, tais como 0 tratamento de resíduos e alimentação saudável, podem ser abordados de modo complexo. Sobre a temática da alimentação, por exemplo, um entendimento mais próximo da realidade de que alimentar-se adequadamente, muitas vezes, é economicamente inviável, devido aos custos de alimentos orgânicos. Neste caso, os alunos seriam convidados a encontrar estratégias de melhoria de qualidade de vida adequadas a sua realidade socioeconômica.

0 segundo princípio consiste em desenvolver uma prática que esteja aberta aos etnosaberes, isto é, aos saberes populares. Essa abertura deve ser pensada como uma oportunidade de aproximar diferentes modos de saber, percebendo as suas possibilidades e limitações. Não trata-se assim de apenas reunir e catalogar informações, mas de discutir e de refletir sobre a epistemologia desses modos peculiares de ver o mundo, reconhecendo que há aprendizagens válidas que ocorrem fora do espaço escolar. Perceber a relação existente entre 0 canto de algumas aves e determinadas lendas, por exemplo, permitiria entender que o homem não só apropria-se dos elementos naturais, mas constrói simbologias e crenças sobre ele.

0 terceiro princípio consiste em pensar a escola como um fórum de participação social. A escola, como destacado no início deste artigo, é uma instituição do tempo presente, que não deve apenas ser pensada só como local de ensinar algo a alguém, mas sim como um elemento catalisador de novas relações e novas aprendizagens. Pensar em uma escola organizada como um fórum, implica reconhecer 0 valor das aprendizagens cotidianas e dos conhecimentos locais e não generalizáveis. Trata-se assim de reconhecer que dentro da cultura local ou até mesmo de micro-culturas existem saberes válidos e que podem ser utilizados para agir perante ao mundo.

0 quarto princípio refere-se a uma escola para os Anos Iniciais que dê ênfase aos processos e não aos produtos. Especificamente no Ensino de Ciências, trata de reconhecer que ensinar não é sinônimo de transmitir um conjunto de fatos ou informações, mas sim auxiliar os estudantes no 
desenvolvimento de um modo singular de compreender o mundo. 0 foco dos processos deve-se ao fato da incerteza do futuro, em que não há garantias que os fazeres atuais serão adequados para a solução de problemas vindouros.

0 quinto princípio de uma pedagogia que busque desenvolver a humildade intelectual é o reconhecimento que a criança que frequenta a escola é multidimensional e um sujeito epistêmico. Multidimensional pelo fato de sua identidade ser emergente de uma rede complexa de relações, nas quais se relacionam aspectos genéticos/biológicos, culturais e sociais. A compreensão dela como sujeito epistêmico envolve percebê-la não como um aprendente, mas sim como um sujeito que possui saberes que estão intimamente associados ao seu modo de ser. Assim, o aprender, muito mais do que reter informações, requer alterar o modo de relacionar-se consigo mesmo.

Por fim, uma escola voltada para o desenvolvimento da humildade intelectual precisa ser uma escola que promova constantemente a dúvida. Uma escola que esteja aberta ao incerto e que tenha uma estrutura organizacional flexível, não estabelecendo marcos prévios a serem atingidos. A uma escola que envolve os estudantes e a si mesmo em uma contínua espiral generativa que promove 0 desenvolvimento permanente.

\section{REFERÊNCIAS}

BARBIER, R. A pesquisa-ação. Brasília: Liber Livro, 2004.

BENDER, W. N. Aprendizagem baseada em Projetos: Educação diferenciada para o Século XXI. Porto Alegre: Penso, 2014.

BIKLEN, S. K.; BOGDAN, R. C. A investigação qualitativa em educação. Porto/Portugal: Porto Editora, 1994.

BIZZO, N. Ciências: fácil ou difícil? São Paulo: Editora Ática, 2001.

BRITO, A. N. de. Da natureza humana e do ensino de virtudes. In.: DALLA COSTA, A. A.; ZAR0, J.; COSTA SILVA, J. Educação Humanizadora e os desafios éticos na sociedade pós-moderna. Santa Maria: Biblos, 2015. p. 153-170.

BROUGĖRE, G. Vida cotidiana e aprendizagens. In.: BROUGĖRE, G.; ULMANN, A. L. Aprender pela vida cotidiana. Campinas, SP: Editores Associados, 2012. p.11-24.

BUSKE, R.; SANTOS, M. L. B.; TEMPO, D. S. A visão sobre cientistas e ciências presentes entre alunos do Ensino Fundamental. Anais do Encontro Nacional de Pesquisa em Educação em Ciências. X Encontro Nacional de Pesquisa em Educação em Ciências. Águas de Lindóia, SP. Novembro de 2015.

CACHAPUZ, A. et al A necessária renovação do Ensino das Ciências. São Paulo: Cortez, 2005.

CARVALHO, A. M. P. Uma metodologia de pesquisa para estudar os processos de ensino e aprendizagem em salas de aula. In.: SANTOS, F. M. T. dos; GREGA, I. M. (org). A pesquisa em Ensino de Ciências no Brasil e suas metodologias. ljuí: Editora ljuí, 2007, p. 13-48.

CHASSOT, A. Alfabetização Científica: questões e desafios para a educação. ljuí: Editora Unijuí, 2014. 
CNS. Conselho Nacional da Saúde. Resolução $\mathbf{n}^{0} \mathbf{5 1 0}$ de $\mathbf{0 7}$ de abril de 2016. Disponível em: https://bit.ly/3Czm0IC. Acesso em 05 dez. 2020.

CORSARO, W. A. Sociologia da Infância. Porto Alegre: Artmed, 2011.

DAHLBERG, G.; MOSS, P.; PENCE, A. Qualidade na Educação da Primeira Infância: perspectivas pós-modernas. Porto Alegre: Penso, 2019.

DEWEY, J. Democracia e Educação. São Paulo: Companhia Editora Nacional, 1979.

ECCO, I. Do legado freireano: Virtudes docentes para a educação humanizadora. In.: DALLA COSTA, A. A.; ZAR0, J.; COSTA SILVA, J. Educação Humanizadora e os desafios éticos na sociedade pós-moderna. Santa Maria: Biblos, 2015. p. 171-180.

FERREIRA, H. da C. A teoria piagetiana da equilibração e as suas consequências educacionais. Bragança/Portugal: Instituto Politécnico de Bragança, 2003.

FREIRE, P. Pedagogia da Autonomia. São Paulo: Paz e Terra, 2011a.

FREIRE, P. Pedagogia do Oprimido. São Paulo: Paz e Terra, 2011b.

FRIEDMANN, A. A vez e a voz das crianças. Escutas Antropológicas e Poéticas das Infâncias. São Paulo: Panda Books, 2020.

GADAMER, H. G. Verdade e Método II: complementos e índices. Petrópolis, RJ: Vozes, 2004.

HOYUELOS, A. A Estética no pensamento e na obra de Loris Malaguzzi. São Paulo: Phorte Editora, 2020.

KATZ, L. 0 que podemos aprender com Reggio Emilia? In.: EDWARDS, C.; GANDINI, L.;FORMAN, G, (org). As Cem Linguagens da Criança: A abordagem de Reggio Emilia na educação da primeira infância. Porto Alegre: Editora Penso, 2016. p. 37-56.

L'ECUYER, C. Educar na curiosidade: A criança como protagonista da sua educação. São Paulo: Edições Fons Sapientiae, 2015.

LEERNER, P. de. A experiência do migrante: a aprendizagem como ruptura subjetiva. In.: BROUGÈRE, G.; ULMANN, A.L. Aprender pela vida cotidiana. Campinas, SP: Editores Associados, 2012. p.49-64

LIVIO, M. Por quê? 0 que nos torna curiosos. Rio de Janeiro: Record, 2018.

LORENZON, M. A espiral investigativa como uma estratégia de desenvolvimento da Alfabetização Científica nos Anos Iniciais do Ensino Fundamental. Dissertação (Mestrado) - Curso de Ensino, Universidade do Vale do Taquari Univates, Lajeado: 2018. 
LORENZON, M. Modernidade, Ciência e Ética: Algumas reflexões para pensar um ensino para a compreensão humana. Tecnia, [S.I.], v. 5, n. 2, p. 14-30, dez. 2020. ISSN 2526-2130.

LORENZON, M. ; OLIVEIRA, E. C.; DEL PINO, J. C. Possíveis confluências entre alfabetização científica e ação dialógica nos processos de formação do sujeito. Revista Thema, 17(1), 210-220.

.; SILVA, J. S. da. A Espiral Investigativa no currículo escolar: desterritorializando a sala de aula. In.: STROHSCHOEN, A. A. G. et al. Espaços não formais de ensino: potencializando a aprendizagem. Lajeado: Ed. Univates, 2020. p. 77-87.

MALAGUZZI, L. De jeito nenhum. As cem estão lá. EDWARDS, C.; GANDINI, L.; FORMAN, G. As Cem Linguagens da Criança: A experiência de Reggio Emilia em transformação. Porto Alegre: Editora Penso, 2016. p. 20-23.

MORAES, R. ; GALIAZZI, M. do C. Análise Textual Discursiva. ljuí: Ed. Unijuí, 2011.

MORAES, R. Uma tempestade de luz: a compreensão possibilitada pela Análise Textual Discursiva. In.: MORAES, R.; GALIAZZI, M. do C. Análise Textual Discursiva. ljuí: Ed. Unijuí, 2011. p. 11-46.

MURARO, D. N. 0 papel do interesse na democracia e na educação. Educação em Foco. Ano 22. n. 38. set/dez. 2019. p. 66-90.

OLIVEIRA-FORMOSINHO, J.; FORMOSINHO, J. Pedagogia em participação: em busca de uma práxis holística. In.: OLIVEIRA-FORMOSINHO, J.; PASCAL, J. Documentação pedagógica e avaliação na Educação Infantil: um caminho para a transformação. Porto Alegre: Penso, 2019. p. 26-58.

OLIVEIRA-FORMOSINHO, J.; FORMOSINHO, J. Pedagogias transmissivas e pedagogias participativas na escola de massas. In.: OLIVEIRA-FORMOSINHO, J.; PASCAL, J. Documentação pedagógica e avaliação na Educação Infantil: um caminho para a transformação. Porto Alegre: Penso, 2020. p. 3-25.

REDIN, E. Humildade. In.: STRECK, D. R.; REDIN, E.; ZITKOSKI, J. J. Dicionário Paulo Freire. Belo Horizonte: Autêntica Editora, 2010. p. 212-213.

RESNICK, M. Jardim de Infância para a vida toda: por uma aprendizagem criativa, mão na massa e relevante para todos. Porto Alegre: Penso, 2020.

RIERA, M. A. Do olhar ao observar. In.: HOYUELOS, A.; RIERA, M. A. Complexidade e Relações na Educação Infantil. São Paulo: Phorte, 2019. p. 73-116.

RINALDI, C. Diálogos com Reggio Emilia. Escutar, investigar e aprender. Paz e Terra: Rio de Janeiro, 2016.

SANTOS, B. Para um novo senso comum: a ciência, o direito e a política na transição paradigmática. São Paulo: Cortez, 2011.

SCHUCK, R. J.; LORENZON, M. Ein zwischen de construção de sentido na ação dialógica: olhar a dialogicidade de Freire a partir da hermenêutica. Revista Pedagógica. v. 19. n. 4. p. 63-79. 
SERRES, M. Polegarzinha. Rio de Janeiro: Bertrand Brasil, 2013.

SILVA, J. S. da. 0 Planejamento no Enfoque Emergente: Uma experiência no $1^{0}$ Ano do Ensino Fundamental de Nove Anos. Tese (doutorado) - Universidade Federal do Rio Grande do Sul, Faculdade de Educação, Programa de Pós-Graduação em Educação, Porto Alegre: 2011.

THIOLLENT, M. Metodologia da Pesquisa-Ação. São Paulo: Cortez, 2004.

RECEBIDO EM: 19 abr. 2021

CONCLUÍDO EM: 31 ago. 2021 